\title{
The Control of DBPs Formation from Different Organics by Chloramine Disinfection
}

\author{
Wang Xuejiao ${ }^{1, a}$, Yan Wenzhou ${ }^{2}$ \\ ${ }^{1}$ Henan electrical power survey and design institute, Zhengzhou, 450007, China \\ ${ }^{2}$ Henan electrical power survey and design institute, Zhengzhou, 450007, China \\ a email: wangxuejiao-heny@powerchina.cn
}

Keywords: Chloramine, Disinfection Products, Hydrophilic, Hydrophobic, Molecular Size.

\begin{abstract}
The organics in the water after advanced treated and to be disinfected are classified basing on different characteristics. Compared with chlorination, the control of DBPs formation from different organics by chloramination is studied. The test results show that, the chloramine can reduces the TTHM and THAA formation from hydrophilic organics by $90.8 \%$ and $77.5 \%$, and from organics with molecular size $<1 \mathrm{KDa}$ by $84.0 \%$ and $74.2 \%$. In addition, the reduction percentages of DBPs formation increases with the deceasing of molecular size.
\end{abstract}

\section{Introduction}

Since the chlorine disinfection byproducts (DBPs) are discovered in drinking water, the carcinogenic risk from them receives serious attention. However, the chlorine disinfection is still popular at most areas because of its low cost, easy operation and mature technology. So, the studies on how to control the DBPs in drinking water are more and more positively in china. The relative research [1] shows that, comparing with free chlorine, the chloramine disinfection could reduce the formation of DBPs.

Natural organic matter (NOM), a complex mixed system, is the main precursor of the DBPs in water. So, the organics need to be classified and studied based on different characteristics. The common classification methods are membrane separation and resin separation [2].

In this paper, considering the water of Huangpu River is of high ammonia concentration and complex organics, the effluent from a pilot process in one water plant in Shanghai has been classified, and the control of chloramine disinfection on DBPs formation from different organics is studied for providing some theory for application of the chloramine disinfection.

\section{Test}

\section{Material and Reagent}

The chloramine stock solution is prepared by sodium hypochlorite ( $\mathrm{NaClO}$ ) solution and ammonium chloride $\left(\mathrm{NH}_{4} \mathrm{Cl}\right)$ solution. In phosphate buffer of $\mathrm{pH} 8.3 \pm 0.1$, the $\mathrm{NaClO}$ is added after the $\mathrm{NH}_{4} \mathrm{Cl}$, then mixing for 30 minutes in dark place. The $\mathrm{NH}_{2} \mathrm{Cl}$ concentration is to be measured at every time the stock solution is used. The $\mathrm{NaClO}$ solution is for commercial, and the active chlorine concentration is titrated by iodometry method. The other reagents $\left(\mathrm{NH}_{4} \mathrm{Cl}, \mathrm{NaOH}\right.$, and $\left.\mathrm{H}_{2} \mathrm{SO}_{4}\right)$ are analytically pure, so these solutions are prepared by deionized water.

\section{Testing Method}

The organics of the water samples are separated by membranes holding different molecular size $\left(30 \times 10^{3} \mathrm{Da}, 10 \times 10^{3} \mathrm{Da}, 3 \times 10^{3} \mathrm{Da}, 1 \times 10^{3} \mathrm{Da}\right)$ [3], and the characteristics of formation into DBPs are studied. The resins of XAD-8 and XAD-4 are used to separate the hydrophilic and hydrophobic organics [4], and basing on structural analysis, the characteristics of formation into DBPs are studied too. 
The water samples are added with chlorine and chloramine respectively both with a concentration of $3 \mathrm{mg} / \mathrm{L}$, and stored in the $40 \mathrm{ML}$ ampoules which are kept in constant temperature incubator. After 24 hours, the trihalomethanes (THMs) and haloacetic acids (HAAs) are measured.

\section{Analysis Method}

The DPD spectrophotometric method [5] is used for measuring the concentration of $\mathrm{NH}_{2} \mathrm{Cl}$ and the $\mathrm{pH}$ value is measured by $\mathrm{PH}$ meter named PHS-3C. The THMs are detected by liquid-liquid extraction and gas chromatography with EDC. The HAAs are detected by trace extraction derivative capillary gas chromatography [6].

\section{Results and Discussion}

\section{DBPs Formation from Different Kind of Organics}

According to the principle of the dissolution in the similar material structure, the highly polar organics have a strong affinity with water, and the weakly polar organics have a weak affinity with water, because $\mathrm{H}_{2} \mathrm{O}$ is polar molecular. So in this study, the organics of water samples are separated into hydrophilic, strongly hydrophobic and weakly hydrophobic organics.

\section{1) Natural Organics Composition}

The water samples are taken from the effluent of the pilot process in a water plant in Shanghai, which takes the raw water from Huangpu River, and the TOC of the water sample is 3.83mg/L. Figure 1 shows the organics composition by percentage.

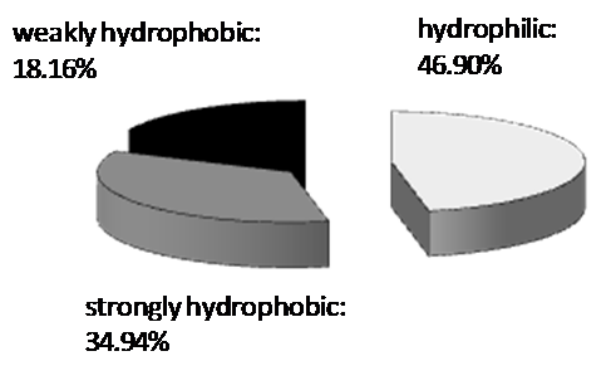

Fig.1 Organics composition by percentage

\section{2) Influence of Chloramine Disinfection}

Three groups of water samples with different organics are added with $3 \mathrm{mg} / \mathrm{L}$ chlorine and chloramines respectively, and the DBPs formation are measured after 24 hours. The results are indicated in figure 2 and 3.

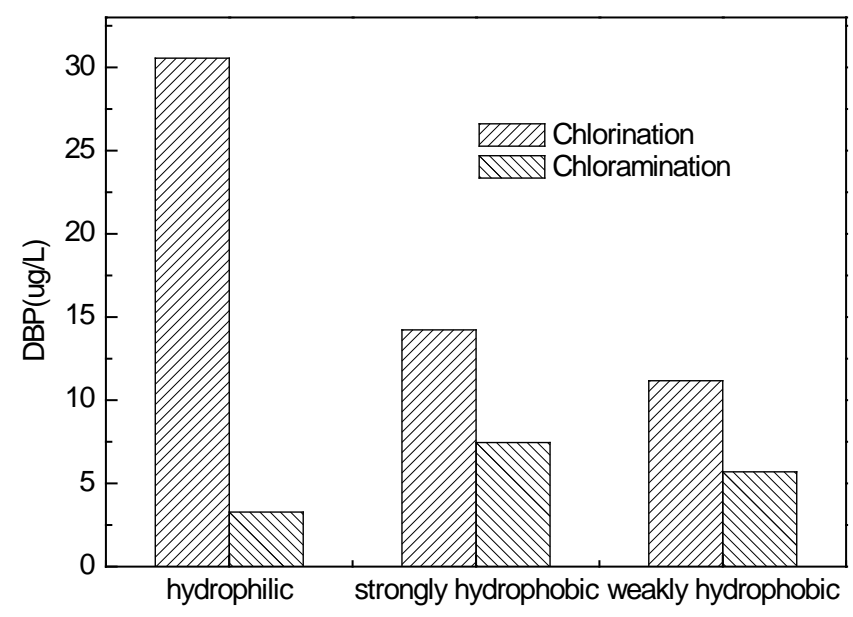

Fig.2 Control of chloramine on the DBPs formation from different organics 
Figure 2 shows the control of chloramine on the formation of DBPs from different organics. For hydrophilic organics, the chloramine disinfection greatly reduces the DBPs formation by the highest percentage of $89.3 \%$ comparing with chlorine disinfection. For strongly hydrophobic and weakly hydrophobic organics, the controls of DBPs formation are nearly the same, by $47.6 \%$ and $49.05 \%$ respectively. Therefore, from this test, the chloramine disinfection can obviously reduce the DBPs formation of the pilot process effluent, for the hydrophilic organics account for a largest percentage of the all organics.

Figure 3 shows the testing results of chloramine on the different DBPs formation from hydrophilic organics. After 24 hours of reaction, the production of $\mathrm{CHCl}_{2} \mathrm{Br}$ and $\mathrm{CHClBr}_{2}$ decrease from $9.69 \mu \mathrm{g} / \mathrm{L}$ and $16.22 \mu \mathrm{g} / \mathrm{L}$ to zero detected and $1.43 \mu \mathrm{g} / \mathrm{L}$ respectively, and the percentage reduction reaches up to $91.2 \%$. Chloramine has poor effect on control of $\mathrm{CHCl}_{3}$ formation. The

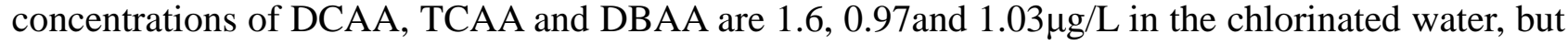
only the TCAA of $0.81 \mu \mathrm{g} / \mathrm{L}$ is detected in the water disinfected by chloramine. To sum up, chloramine disinfection reduces the TTHM and THAA formation from hydrophilic organics by $90.8 \%$ and $77.5 \%$.

Relevant data show that, the hydrophilic organics are mostly aliphatic and nitrogenous materials [7], which are important precursors of DBPs. When chloramine is taken as the disinfectant, the control effect on DBPs formation could be better for this kind of organics for chloramine has a lower concentration of $\mathrm{HOCl}$.

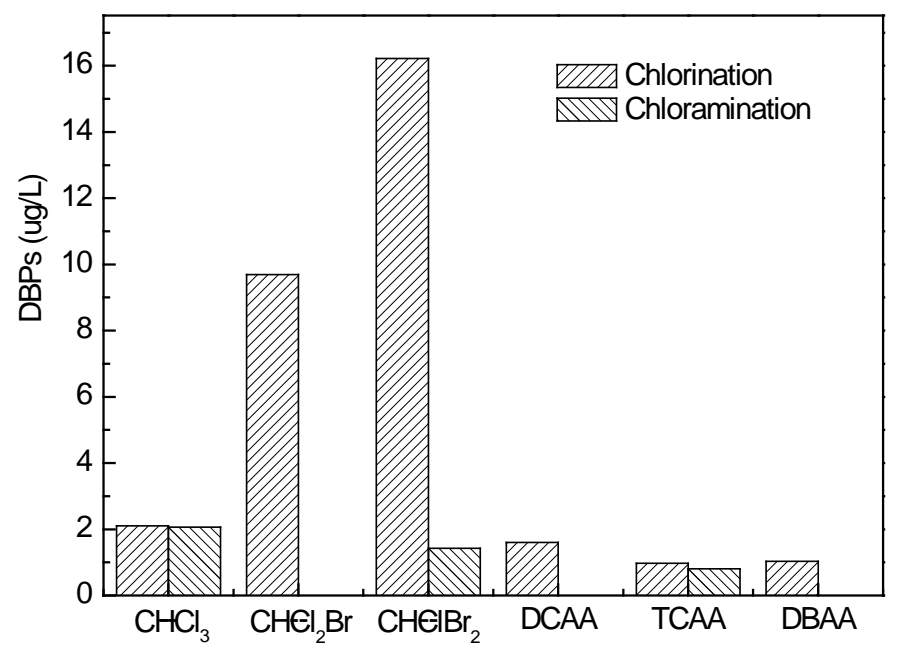

Fig.3 DBPs formation from hydrophilic organics

\section{DBPs Formation from Organics with Different Molecular Size}

\section{1) Organics Composition with Different Molecular Size}

The organics composition with different molecular size is determined and analyzed by ultra-filtration membrane method, and valued as TOC and $\mathrm{UV}_{254}$. The water samples are also taken from the effluent of the same pilot process.

From figure 4, the percentages of organics with molecular size $<1 \mathrm{KDa}$ are $92.97 \%$ as TOC and $88.35 \%$ as $\mathrm{UV}_{254}$, and the percentages of organics with molecular size $30 \mathrm{KDa}-0.45 \mu \mathrm{m}$ are zero as TOC and $1.94 \%$ as $\mathrm{UV}_{254}$. This result indicate that, after advanced treatment, which is the conventional process plus the pre-ozonation and activated carbon filtration, the water primarily contains the organics with molecular size $<1 \mathrm{KDa}$, which is due to the pre-ozonation. 


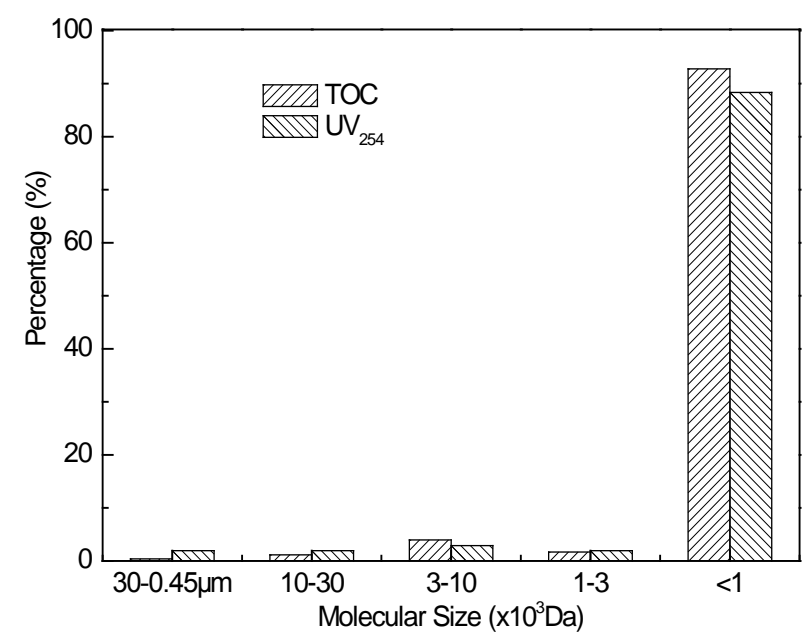

Fig.4 Molecular size distribution of organics

\section{2) Influence of Chloramine Disinfection}

The water samples with organics of different molecular size are added with $3 \mathrm{mg} / \mathrm{L}$ chlorine and chloramines respectively, and the DBPs formation are measured after 24 hours of reaction. The results are indicated in figure 5 and 6.

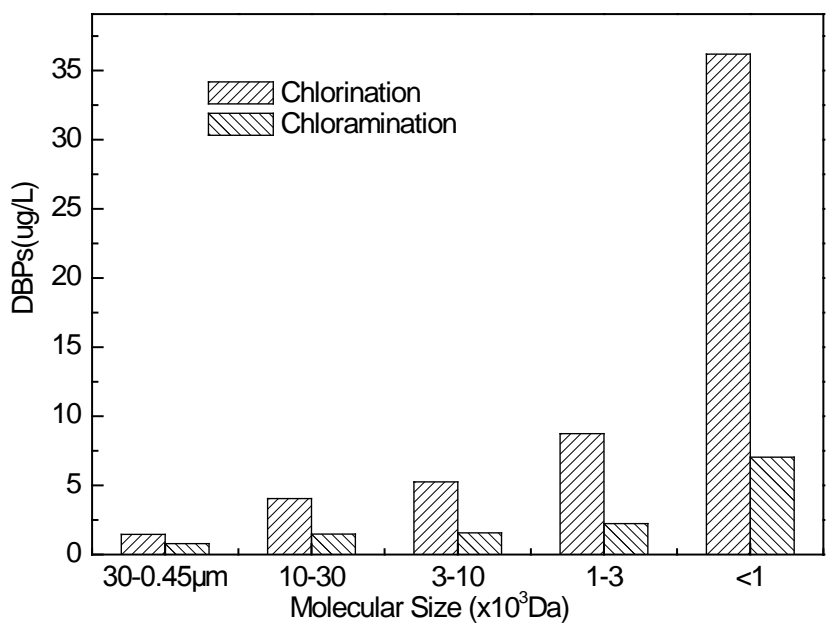

Fig.5 Control of chloramine on DBPs formation from organics with different molecular size

The figure 5 shows, the reduction percentages of DBPs formation from organics with different molecular size (30KDa 0.45 $\mu \mathrm{m}, 10 \sim 30 \mathrm{KDa}, 3 \sim 10 \mathrm{KDa}, 1 \sim 3 \mathrm{KDa}$ and $<1 \mathrm{KDa}$ ) are 45.89\%, 63.46\%, $70.10 \%, 74.37 \%$ and $80.55 \%$ respectively, which shows a rule of that the percentage increases with the deceasing of molecular size. For the primary organics in the water after advance treatment is the organics with molecular size $<1 \mathrm{KDa}$, the chloramine disinfection can control the DBPs formation effectively.

According to figure 6, the reduction percentages of $\mathrm{CHCl}_{3} 、 \mathrm{CHCl}_{2} \mathrm{Br} 、 \mathrm{CHClBr}_{2} 、 \mathrm{DCAA} 、 \mathrm{TCAA}$ and DBAA formation from organics with molecular size <1KDa are 50.29\%, 89.56\%, $90.37 \%, 72.76 \%, 56.06 \%$ and $100 \%$ respectively, which indicates that the chloramine disinfection controls the bromide DBPs formation effectively, and the organics with molecular size <1KDa maybe the hydrophilic organics. 


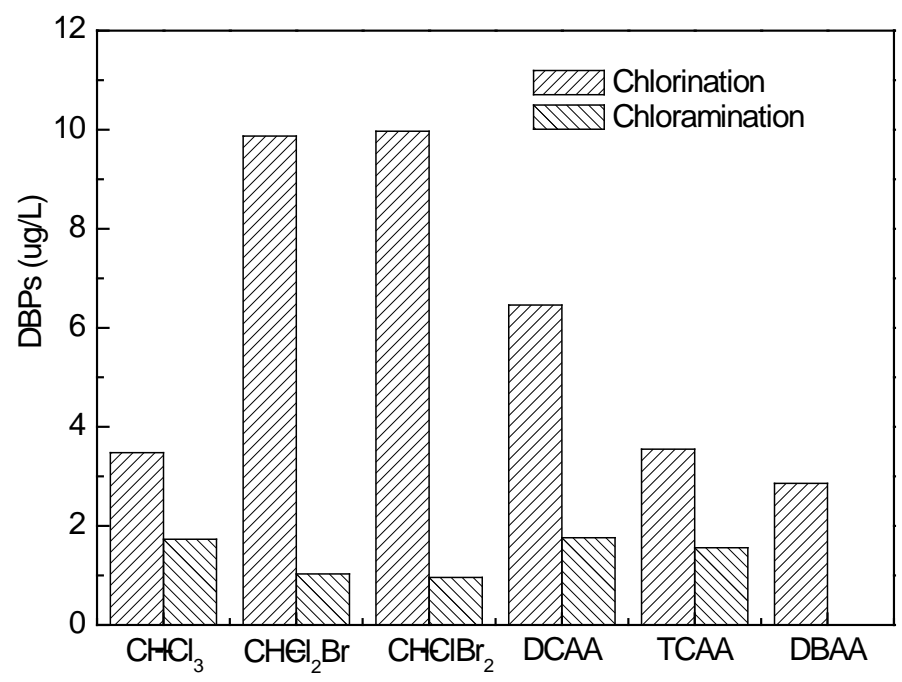

Fig.6 DBPs formation from organics with molecular size $<1 \mathrm{KDa}$

\section{Conclusion}

In summary, the chloramine disinfection can reduce the DBPs formation effectively, but the effect differs depending on the characteristics of organics in the water to be disinfected. For the water of Huangpu River treated by advanced process, the chloramine disinfection is an efficient control measure for reducing the DBPs formation, because hydrophilic organics and organics with molecular size $<1 \mathrm{KDa}$ account for the larger percentages.

From this test, compared with chlorine disinfection, the chloramine can reduces the TTHM and THAA formation from hydrophilic organics by $90.8 \%$ and $77.5 \%$, and from organics with molecular size $<1 \mathrm{KDa}$ by $84.0 \%$ and $74.2 \%$. in addition, the reduction percentages of DBPs formation increases with the deceasing of molecular size.

\section{References}

[1] Xin Yang and Chii Shang. Chlorination Byproduct Formation in the Presence of Humic Acid, Model Nitrogenous Organic Compounds, Ammonia, and Bromide [J]. Environ. Sci. Technol., 2004, 38(19): 4995-5001.

[2] L. Amench, Fractionation of NOM from Surface Water Using Macroporous Resins [J]. Water Research, 1997, 31(9): 2987-2997.

[3] Amy G. L., Sierka R. A., Bedessem J.. Molecular Size Distribution of Dissolved Organic Matter [J]. Journal of AWWA, 1992, 84 (6): 67-65.

[4] Panyapinyopol Bunyarit, Marhaba Taha F., Kanokkantapong, Vorapot. Characterization of Precursors to Trihalomethanes Formation in Bangkok Source Water [J]. Journal of Hazardous Materials, 2005, 120 (1-3): 229-236.

[5] Sun Qing-ping. Separate Determination of Chloramines in Chlorinated Water [J]. CHINA WATER \& WASTEWATER, 2005,21(11): 98-100.

[6] Wu Hai-hui, Gao Nai-yun, Wan Rong-fang, et al. Effect and Kinetics of Haloacetic acids Degradation by Advanced Oxidation Processes [J]. JOURNALOF HARBIN INSTITUTE OF TECHNOLOGY, 2007, 39(12): 1974-1978.

[7] L.B.Barber, J.A.Leenheer, T.I.Noyes, et al. Nature and Transformation of Dissolved Organic Matter in Treatment Wetlands [J]. Environ. Sci. Technol., 2001, 35(24): 4805-4816. 